\title{
GnRH antagonist weakens endometrial stromal cells growth ability by decreasing c-kit receptor expression
}

Ding-Fei Xu ${ }^{1,2}$, Pei-Pei Liu ${ }^{1,2}$, Lu Fan ${ }^{1,2}$, Qi Xie ${ }^{1}$, Zhi-Qin Zhang ${ }^{2}$, Li-Qun Wang ${ }^{1,3^{*}}$, Qiong-Fang Wu ${ }^{1,2^{*}}$ and Jun Tan ${ }^{1,2^{*}}$

\begin{abstract}
Background: Several surveys have reported that patients treated with gonadotropin-releasing hormone antagonist (GnRH-ant) protocol showed a significantly lower rate of implantation and clinical pregnancy compared to GnRH agonist ( $\mathrm{GnRH}-\mathrm{a}$ ) protocol during in vitro fertilization-fresh embryo transfer. Subsequent studies imputed this poor outcome to the negative effects of $\mathrm{GnRH}$-ant on endometrial receptive. However, the mechanisms were not fully understood.

Methods: The clinical data of 2815 patients undergoing fresh embryo transfer in our center were analyzed. Human endometrial stromal cells (ESCS) from healthy women undergoing elective pregnancy termination of a normal pregnancy at 8-10 weeks gestation were treated with GnRH-analogs or imatinib (c-kit receptor inhibitor). CCK8 and Flow cytometry were used to investigated the growth ability of ESCs. Immunofluorescence staining and western blot was used to detected the target proteins.

Results: The clinical data showed that the endometrial thickness on HCG Day were significantly lower in GnRH-ant group. Although no difference of embryo quality in these two groups, GnRH-ant group showed remarkably decreased rate of HCG positive, embryo implantation and pregnancy. Moreover, GnRH-ant significantly reduced the proliferation and induced the apoptosis of ESCs. Furthermore, the expression and activation of c-kit receptor, which played pivotal roles during embryo implantation, were observably decreased by GnRH-ant. Inhibiting the activation of c-kit by imatinib remarkably suppressed the proliferation and promoted the apoptosis of ESCs. Additionally, the phosphorylation of AKT and expression of Cyclin D1, which were closely related with cellular growth, were distinctly lessened after treating with imatinib.
\end{abstract}

Conclusions: In summary, our study showed that GnRH-ant weakened the activization of c-kit receptor by decreasing its expression, causing the impaired growth ability of ESCs. Our findings provided a new insight into the effects of GnRH-ant on endometrium.

Keywords: GnRH-ant, C-kit receptor, ESCs, Growth ability

\footnotetext{
*Correspondence: 1500325038@qq.com; wuqiongfang898@sina.com; tanjun561127@163.com

${ }^{2}$ Reproductive Medicine Center, Maternal and Child Health Hospital Affiliated to Nanchang University, Jiangxi Maternal and Child Health Hospital, Nanchang, Jiangxi 330006, P. R. China

${ }^{3}$ Department of Reproductive Health, Maternal and Child Health Hospital

of Nanchang University, Jiangxi maternal and child health hospital, Nanchang, Jiangxi 330006, P. R. China

Full list of author information is available at the end of the article
}

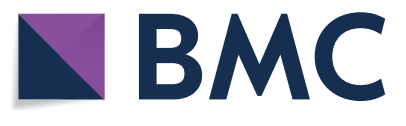

(c) The Author(s) 2022. Open Access This article is licensed under a Creative Commons Attribution 4.0 International License, which permits use, sharing, adaptation, distribution and reproduction in any medium or format, as long as you give appropriate credit to the original author(s) and the source, provide a link to the Creative Commons licence, and indicate if changes were made. The images or other third party material in this article are included in the article's Creative Commons licence, unless indicated otherwise in a credit line to the material. If material is not included in the article's Creative Commons licence and your intended use is not permitted by statutory regulation or exceeds the permitted use, you will need to obtain permission directly from the copyright holder. To view a copy of this licence, visit http://creativecommons.org/licenses/by/4.0/. The Creative Commons Public Domain Dedication waiver (http://creativeco mmons.org/publicdomain/zero/1.0/) applies to the data made available in this article, unless otherwise stated in a credit line to the data. 


\section{Background}

Gonadotropin-releasing hormone antagonist (GnRHant), which could competitively bind with GnRH receptor (GnRHR) and reversibly inhibited hypothalamic-pituitary-gonadal axis, has been used in assisted reproduction for several decades from the first generation to the recent third generation [1]. Based on the superiority of convenience, flexibility and safety, GnRH-ant protocol has been one of the most commonly therapeutic schedules in in vitro fertilization-embryo transfer (IVF-ET) [2]. However, the unsatisfactory clinical outcomes of this protocol, compared to GnRH-agonist (GnRH-a) protocol, has restrained its promotion and application in clinic. Many clinical investigations have reported lower fresh embryo implantation and pregnancy rates in GnRH-ant protocol than those in GnRH-a protocol [3-5]. Similarly, Bukulmez's research also showed a lower HCG positive and clinical pregnancy rate in $\mathrm{GnRH}$-ant protocol when compared to $\mathrm{GnRH}$-a protocol within no difference of embryo quality between these two protocols [6]. Additionally, decreased clinical outcomes from GnRH-ant protocol were only obvsered in fresh embryo transfer but not in freezing embryo transfer [7], suggesting that the adverse effects of $\mathrm{GnRH}$-ant on endometrium might be the key reason.

In fact, many researches have demonstrated that the endometrial thickness could be an important factor which influenced the pregnancy after embryo transfer [8-11]. Patients with endometrial thickness less than $8 \mathrm{~mm}$ experienced lower implantation and pregnancy rate [12]. Significantly, recent studies have proved that patients treated with $\mathrm{GnRH}$-ant protocol developed a remarkably thinner endometrial thickness than patients treated with $\mathrm{GnRH}$-a protocol [13, 14]. These results implied that one of the adverse effects of $\mathrm{GnRH}$-ant on endometrium was to weaken endometrial thickness. Nonetheless, the related molecular mechanism was still unclear.

Previous studies have found the expression of c-kit receptor on embryo and endometrium [15], suggesting the crucial role of c-kit receptor in the process of animal embryo implantation. C-kit receptor belongs to RTK type III family which could be stimulated by stem cell factor (SCF). Activated c-kit receptor was associated with multiple kinds of biological events, including proliferation, differentiation, migration and apoptosis, in many types of cells $[16,17]$. Our previous study reported the expression of c-kit receptor on human embryo and demonstrated that added exogenous SCF to activate c-kit receptor significantly promoted embryo development [18]. Recently, we found the expression of c-kit receptor on human endometrial stromal cells (ESCs). Based on the regulatory function on the growth of many kinds of cells, we speculated that c-kit receptor might also influence the growth of human ESCs. Furthermore, whether its regulatory effect is associated with GnRH-ant is still unknown.

Therefore, the present study was conducted to explore the effects of GnRH-ant and c-kit receptor on the growth of human ESCs, and to investigated the regulatory relationship between $\mathrm{GnRH}$-ant and c-kit receptor.

\section{Methods \\ Reagents}

The following reagents were used in this study: rabbit anti-GnRHR (Abcam, UK), mouse anti-c-kit (CST, USA), rabbit anti-c-kit (CST, USA), rabbit anti-phospho-c-kit (CST, USA), rabbit anti-AKT (CST, USA), rabbit anti-phospho-AKT (CST, USA), rabbit anti-Cyclin D1 (CST, USA), mouse anti- $\beta$-actin (Santa Cruz, USA), Donkey anti rabbit Alexa flour 488 (Thermo Fisher Scientific, USA), Donkey anti rabbit Alexa flour 594 (Thermo Fisher Scientific, USA), GnRH-a (Decapeptyl; Ferring), GnRH-ant (Cetrotide; Serono) and Imatinib (Biovision, USA).

\section{Patients}

The present study retrospectively analyzed the clinical data of 2815 patients undergoing fresh embryo transfer in Reproductive Medicine Center of Jiangxi Maternal and Child Health Hospital from Jan 2016 to Dec 2020. The reasons of infertility were oviduct diseases and/or male factors. The inclusion criteria for all patients included age $\leq 37$ years, body mass index (BMI) of $15-25 \mathrm{~kg} / \mathrm{m}^{2}$, $1.1<$ anti-Müllerian hormone $(\mathrm{AMH})<5.0,5 \leq$ antral follicle count $(\mathrm{AFC}) \leq 20$, and less than twice IVF-ET experiences. Women with a history of the following procedures or disorders were excluded: uterine malformation, ovarian surgery, radiotherapy or chemotherapy, premature ovarian failure, ovarian dysfunction, adenomyosis, polycystic ovarian syndrome, thyroid dysfunction, recurrent implantation failure (failed to achieve a pregnancy more than three times), submucosal fibroids, intrauterine adhesion, hydrosalpinx, and patients (women or men) with abnormal chromosomes.

\section{Study design and groups}

Two thousand eight hundred fifteen patients were classified as GnRH-ant group (563) and GnRH-a group (2252) according to the different protocols. In GnRH-ant group, recombinant human FSH (rhFSH, Merck-Serono, German) treatment began on day 2 or 3 of the menstrual cycle. The initial dosage (112.5-225IU/day) was determined based on age, BMI, AFC, and AMH. The daily dose of rhFSH was adjusted according to ovarian response as monitored by ultrasonography and serum estradiol $\left(E_{2}\right)$ levels. GnRH antagonist (Cetrorelix, Merck Serono, 
Switzerland) at a daily dose of $0.25 \mathrm{mg}$ was started when the largest follicle exceeded $12 \mathrm{~mm}$. Both GnRH antagonist and rhFSH were stopped and a single injection of 6000-8000 IU of hCG (Merck-Serono, German) was administered when the dominant follicle was $\geq 19 \mathrm{~mm}$ in diameter or at least 2 follicles were $\geq 18 \mathrm{~mm}$ in diameter. Oocyte retrieval was performed 36-40 h later under transvaginal ultrasound guidance. In GnRH-a group, a standard full dose of gonadotropin-releasing hormone agonist (administered as a one-time dose of $3.75 \mathrm{mg}$, GnRH agonist, Ipsen, France) was used on the second day of menstrual cycle for down regulation. Pituitary down regulation (Endometrial thickness $\leq 5 \mathrm{~mm}$, serum $\mathrm{FSH}<5$ $\mathrm{mIU} / \mathrm{mL}, \mathrm{LH}<5 \mathrm{mIU} / \mathrm{mL}, \mathrm{E}_{2}<50 \mathrm{pg} / \mathrm{mL}$ ) was confirmed with transvaginal ultrasound and endocrine examination after 28-30 days. The initial dosage (112.5-225 IU/ day) was determined based on age, BMI, AFC, and AMH. The dose of rhFSH were adjusted according to ovarian response as monitored by ultrasonography and serum estradiol levels. The HCG trigger process and oocyte retrieval was the same as described above.

HCG positive rate: HCG concentration was defined by measuring blood 14 days (embryo at day 3 ) or 12 days (blastocyst) after embryo transfer, and the threshold concentration of $\mathrm{HCG}$ positive was $>5 \mathrm{mIU} / \mathrm{mL}$. The HCG positive rate refers to the number of HCG positive patients divided by the total number of patients. Clinical pregnancy rate: fetal heartbeat was used to define clinical pregnancy by ultrasonography 1 month after embryo transfer. The clinical pregnancy rate refers to the number of clinical pregnancy patients divided by the total number of patients. Implantation rate: the number of embryos with fetal heartbeat divided the total number of all transferred embryos.

\section{Embryo assessment}

The embryo assessment criteria were executed as the previously described [18]. A good quality embryo should consist of 7-9 blastomeres with a uniform size, and the fragment proportion should be less than $20 \%$ at day 3 for human 2PN embryos after fertilization. The good quality embryo rate refers to the number of good quality embryos divided by the total number of all embryos. Blastocyst formation was determined and graded by using the system of Gardner and Schoolcraft [19]. The blastulation rate refers to the number of blastocysts divided by the total number of all embryos. The good quality blastulation rate refers to the number of good quality blastocyst divided by the total number of all blastocysts. The assessment was made in a blinded manner by two embryologists. Embryo transfer was conducted on day 3 for embryos or day 5 and day 6 for blastocysts after oocyte retrieval.

\section{Primary human ESCs isolation, culture and treatment}

Primary human decidual ESCs were isolated from the decidual tissue of healthy multipara women (aged 25-32 years) undergoing elective surgical termination of a normal pregnancy at 8 to 10 weeks of gestation. The informed consents from all patients were obtained before the initiation of this study. According to the standard protocol $[20,21]$, the human decidual tissue was minced and treated with type IV collagenase and DNase type I in a shaking water bath at $37^{\circ} \mathrm{C}$ for $90 \mathrm{~min}$. The cell digest was then passed through a $70 \mu \mathrm{m}$ filter, both decidual stromal and epithelial cells were collected. Then, decidual stromal cells were separated from epithelial cells with a $45 \mu \mathrm{m}$ filter. The stromal cells were subsequently pelleted by centrifugation at $1000 \mathrm{rpm}$ for $5 \mathrm{~min}$. The cell pellets were washed once, resuspended, and cultured in Dulbecco modified Eagle medium containing $25 \mathrm{mM}$ glucose, Lglutamine, antibiotics and supplemented with $10 \%$ fetal bovine serum at $37^{\circ} \mathrm{C}$. ESCs was confirmed by detecting the expression of vimentin protein via immunohistochemical analysis (Supplementary Fig. 1). The cells were used after reaching 70-80\% confluence. ESCs were treated for $120 \mathrm{~h}$ with different concentrations of GnRH-a, GnRH-ant $\left(10^{-8}, 10^{-5}\right.$, and $\left.2 \times 10^{-5} \mathrm{~mol} / \mathrm{L}\right)$ or imatinib $(0 \mu \mathrm{M}, 4 \mu \mathrm{M}, 8 \mu \mathrm{M}, 16 \mu \mathrm{M}, 24 \mu \mathrm{M}, 32 \mu \mathrm{M})$. Cells were subsequently collected for cell proliferation assay, flow cytometry and western blot.

\section{Cell proliferation assay}

Five thousand cells/well were planted into 96-well plates in quintuplicate wells. Normally, cells were placed in the culture medium with different concentrations of GnRH analogs for $24,48,72,96$ and $120 \mathrm{~h}$, a total of $10 \mu \mathrm{L}$ CCK 8 reagent (APExBio, USA) was added to each well. After incubating for $2 \mathrm{~h}$ at $37^{\circ} \mathrm{C}$, the absorbance at $450 \mathrm{~nm}$ per well was measured using microplate reader. Each group of experiments was repeated three times.

\section{Flow cytometry}

The suspended cells were collected by centrifugation. Centrifuge $1000 \mathrm{~g}$, centrifugation time $5 \mathrm{~min}$ at $2-8^{\circ} \mathrm{C}$. Cultured cells needed to be digested with EDTA-free trypsin, then terminated with serum-containing medium, centrifuged at $1000 \mathrm{~g}$ for $5 \mathrm{~min}$, supernatant removed, and washed with PBS resuspension. After centrifugal precipitation, the PBS was resuspended, transferred into the flow tube, washed once with PBS, centrifuged at $1000 \mathrm{~g}$ for $5 \mathrm{~min}$, and the supernatant was discarded. Cells were suspended with $400 \mathrm{UL} \times$ Annexin binding solution at a concentration of approximately $1 \times 10^{6}$ cells $/ \mathrm{ml}$. Five UL Annexin V-FITC staining solution (BestBio, China) was added to the cell suspension, gently mixed and incubated for $15 \mathrm{~min}$ at $2-8^{\circ} \mathrm{C}$ in the dark. After adding 10 
Table 1 Comparison of the general information of the two groups of patients

\begin{tabular}{llll}
\hline & GnRH-ant $(\boldsymbol{n = 5 6 3 )}$ & GnRH-a $(\boldsymbol{n}=\mathbf{2 2 5 2})$ & $\boldsymbol{P}$-value \\
\hline Age $(\mathrm{y})$ & $30.99 \pm 4.55$ & $31.01 \pm 4.2$ & 0.9463 \\
BMl $\left(\mathrm{Kg} / \mathrm{m}^{2}\right)$ & $21.7 \pm 5.35$ & $21.67 \pm 3.96$ & 0.9054 \\
Duration of infertility (y) & $4.22 \pm 3.26$ & $4.24 \pm 3.1$ & 0.9202 \\
Antral follicle count $(\mathrm{n})$ & $10.94 \pm 3.96$ & $10.95 \pm 3.71$ & 0.9559 \\
Endometrial thickness $(\mathrm{mm})$ & $7.03 \pm 2.3$ & $7.08 \pm 2.19$ & 0.9508 \\
AMH $(\mathrm{ng} / \mathrm{mL})$ & $2.76 \pm 1.04$ & $2.77 \pm 1.04$ & 0.9292 \\
Basal FSH $(\mathrm{mlU} / \mathrm{mL})$ & $6.19 \pm 2.28$ & $6.48 \pm 1.01$ & 0.7619 \\
Basal $\mathrm{E}_{2}(\mathrm{pg} / \mathrm{mL})$ & $66.86 \pm 16.07$ & $57.28 \pm 23.25$ & 0.2600 \\
Basal P $(\mathrm{ng} / \mathrm{mL})$ & $1.2 \pm 3.33$ & $1.55 \pm 4.26$ & 0.7954 \\
Basal LH $(\mathrm{mlU} / \mathrm{mL})$ & $4.44 \pm 3.79$ & $4.49 \pm 3.45$ & 0.7901 \\
\hline
\end{tabular}

Note: The data were expressed as mean $\pm S D$

Abbreviations: $B M I$ Body Mass Index, $A M H$ anti-mullerian hormone, $F S H$ follicle-stimulating hormone, $L H$ luteinizing hormone, $E_{2}$ estradiol, $P$ progesterone

UL PI staining solution, gently mixed and incubated for $15 \mathrm{~min}$ at $2-8^{\circ} \mathrm{C}$ in the dark. Immediately detected by flow cytometry. Each group of experiments was repeated three times.

\section{Immunofluorescence staining}

The methods were described previously [22]. Cells were fixed with $4 \%$ paraformaldehyde at $4{ }^{\circ} \mathrm{C}$ for $10 \mathrm{~min}$ and washed with PBS three times. The cells were sealed with $2 \%$ triton-100 solution at room temperature for $30 \mathrm{~min}$. The primary antibody diluted by blocking solution was added and incubated overnight at $4{ }^{\circ} \mathrm{C}$. The next day, cells were washed with PBS three times, 5 min each time. The fluorescent secondary antibodies were added and incubated for $1 \mathrm{~h}$ at room temperature in the dark, then the cells were washed with PBS for 3 times, 5 min each time. Fluoroshield mounting medium (containing DAPI) with 1:10 dilution was added and stored at $4{ }^{\circ} \mathrm{C}$ in the dark for fluorescence microscopy observation.

\section{Western blot}

Total proteins were extracted from cells using the RIPA lysis buffer containing protease inhibitors (Applygen, China) and phosphatase inhibitors (Sigma, USA). The protein concentrations were determined by NanoDrop 2000c spectrophotometer using BCA protein assay kit (Applygen, China). After loading equal amount of protein samples, SDS-PAGE (12\% sodium dodecyl sulfate polyacrylamide gel electrophoresis) was performed. The proteins were then transferred to a PVDF membrane (Merck-Millipore, USA). After blocking with Tris buffered saline containing $0.05 \%$ Tween-20 (TBST) and 5\% non-fat dry milk or $5 \%$ BSA for $1 \mathrm{~h}$, the membrane was incubated with corresponding antibodies at $4{ }^{\circ} \mathrm{C}$ overnight, washed in TBST, followed by incubation with the corresponding horseradish peroxidase-conjugated secondary antibodies for $1 \mathrm{~h}$. Visualization of the proteins was detected with ECL chemiluminescence. Beta-actin was used as a loading control. The intensity values were assessed and analyzed with Image J software. ( $n=4$ for per lane).

\section{Statistical analysis}

Statistical analyses were conducted by using SPSS 24.0 software (SASInstitute Inc.), and all data were expressed as means \pm standard errors of the means (s.e.m.s) or percentage (\%). Results among experimental groups were analyzed by student's t-test or one-way ANOVA. For all tests, $P$-value $<0.05$ was considered statistically significant.

Table 2 Comparison of the effect of ovulation promotion between two groups of patients

\begin{tabular}{llll}
\hline & $\begin{array}{l}\text { GnRH-ant } \\
(\boldsymbol{n}=\mathbf{5 6 3})\end{array}$ & GnRH-a $(\boldsymbol{n}=\mathbf{2 2 5 2})$ & $\boldsymbol{P}$-value \\
\hline $\begin{array}{l}\text { Initial dose of Gn } \\
\text { (IU) }\end{array}$ & $212.92 \pm 75.17$ & $177.83 \pm 69.62$ & 0.0000 \\
$\begin{array}{l}\text { Duration of Gn } \\
\text { used (d) }\end{array}$ & $9.11 \pm 1.47$ & $11.19 \pm 1.92$ & 0.0000 \\
$\begin{array}{l}\text { Total dose of Gn } \\
\text { (IU) }\end{array}$ & $2132.1 \pm 631.08$ & $2391.2 \pm 857.17$ & 0.0000 \\
$\begin{array}{l}\text { Endometrial thick- } \\
\text { ness on HCG day } \\
(\mathrm{mm})\end{array}$ & $7.51 \pm 2.27$ & $9.09 \pm 2.61$ & 0.0000 \\
$\begin{array}{l}\mathrm{E}_{2} \text { on HCG day (pg/ } \\
\mathrm{mL})\end{array}$ & $2041.17 \pm 1170.34$ & $2080.32 \pm 1022.21$ & 0.4728 \\
$\begin{array}{l}\text { LH on HCG day } \\
(\mathrm{mlU} / \mathrm{mL})\end{array}$ & $2.14 \pm 1.51$ & $1.06 \pm 0.94$ & 0.0000 \\
$\begin{array}{l}\text { P on HCG day (ng/ } \\
\mathrm{mL})\end{array}$ & $0.86 \pm 1.21$ & $0.8 \pm 1.46$ & 0.3471 \\
\hline
\end{tabular}

Note: The data were expressed as mean \pm SD

Abbreviations: Gn gonadotropin, HCG Human Chorionic Gonadotropin, LH luteinizing hormone, $E_{2}$ estradiol, $P$ progesterone 
Table 3 Comparison of clinical outcomes between two groups of patients

\begin{tabular}{llll}
\hline & GnRH-ant $(\boldsymbol{n}=\mathbf{5 6 3})$ & GnRH-a $(\boldsymbol{n}=\mathbf{2 2 5 2})$ & P-value \\
\hline Number of oocytes retrieved & $11.26 \pm 3.65$ & $11.44 \pm 3.58$ & 0.8006 \\
2PN fertilization rate (\%) & 60.3 & 61.64 & 0.2813 \\
2PN cleavage rate (\%) & 95.75 & 95.82 & 0.8686 \\
High quality embryo at day 3 rate (\%) & 28.59 & 28.22 & 0.6765 \\
High quality blastulation rate (\%) & 36.2 & 34.01 & 0.1091 \\
Number of transfer embryos & $1.91 \pm 1.7$ & $1.88 \pm 1.83$ & 0.1627 \\
HCG positive rate (\%) & 62.95 & 71.72 & 0.0018 \\
Implantation rate (\%) & 40 & 47.62 & 0.0007 \\
Clinical pregnancy rate (\%) & 55.41 & 64.04 & 0.0038 \\
\multicolumn{2}{c}{4 Live birth rate (\%) } & & 50.64 \\
\hline
\end{tabular}

Abbreviations: PN pronucleus, HCG Human Chorionic Gonadotropin

\section{Results}

\section{General characteristics}

No differences were found in general characteristics between these two groups (Table 1).

\section{Comparison of the IVF outcomes between GnRH-ant and $\mathrm{GnRH}-\mathrm{a}$ groups}

Firstly, we compared the effects of ovulation promotion between GnRH-ant and GnRH-a groups (Table 2).
Among the two groups, the levels of $\mathrm{E}_{2}$ and P on HCG day were similar $(P>0.05)$, but the initial dose of gonadotropin (Gn), duration of $\mathrm{Gn}$ used, total dose of $\mathrm{Gn}$ and endometrial thickness on HCG Day were significantly lower in $\mathrm{GnRH}$-ant group than those in $\mathrm{GnRH}$-a group $(P<0.01)$, whereas the LH level on HCG Day was higher in $\mathrm{GnRH}$-ant group $(P<0.01)$. Then, we investigated the clinical outcomes from these two groups (Table 3). There were no differences in the number of oocytes retrieved,

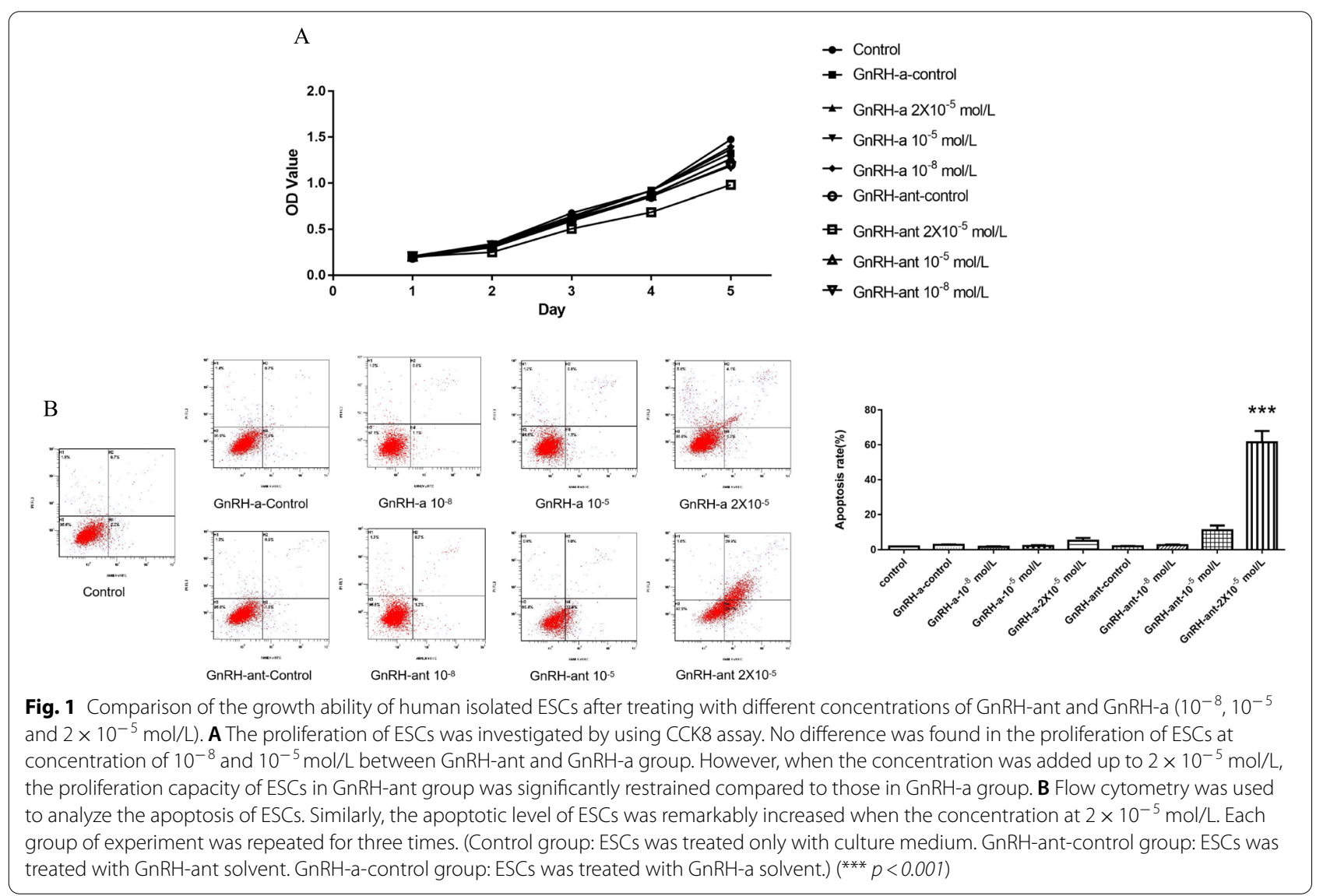


2PN fertilization rate, 2PN cleavage rate, high quality embryo rate and high quality blastulation rate between these two groups $(P>0.05)$. However, $\mathrm{GnRH}$-ant group showed remarkably decreased rate of HCG positive, embryonical implantation and clinical pregnancy when compared to $\mathrm{GnRH}-\mathrm{a}$ group $(P<0.01)$, implying the worse clinical outcomes in GnRH-ant group.

\section{GnRH-ant reduced the proliferation and induced the apoptosis of human isolated ESCs}

CCK8 and Flow cytometry were used to investigate the effects of GnRH-ant on the growth ability of human isolated ESCs, which was confirmed by immunohistochemical analysis (Supplementary Fig. 1). Little differences were found in the concentrations of $\mathrm{GnRH}$-ant and $\mathrm{GnRH}-\mathrm{a}$ at $10^{-8}$ and $10^{-5} \mathrm{~mol} / \mathrm{L}$. When the concentration was elevated to $2 \times 10^{-5} \mathrm{~mol} / \mathrm{L}, \mathrm{GnRH}$-ant obviously reduced the proliferation and induced the apoptosis of ESCs (Fig. 1).

\section{GnRH-ant decreased the expression of c-kit receptor in human isolated ESCs}

As shown in the results of immunofluorescence staining, GnRH receptor and c-kit receptor were co-expressed on human isolated ESCs, indicating a possible potential regulatory relationship between these two receptors (Fig. 2A). After treating human isolated ESCs with the concentration of GnRH-ant and GnRH-a at $2 \times 10^{-5}$ $\mathrm{mol} / \mathrm{L}$, we found significantly reduced expression of c-kit receptor and phosphorylation c-kit receptor in GnRHant group (Fig. 2B), suggesting c-kit signaling was attenuated by GnRH-ant.

\section{C-kit receptor regulated the growth ability of human isolated ESCs through AKT signaling pathway}

Cultured human isolated ESCs were treated with different concentrations of imatinib $(0 \mu \mathrm{M}, 4 \mu \mathrm{M}, 8 \mu \mathrm{M}, 16 \mu \mathrm{M}$, $24 \mu \mathrm{M}, 32 \mu \mathrm{M})$ to confirm the ideal dosage required to suppress the c-kit receptor activation. The results showed

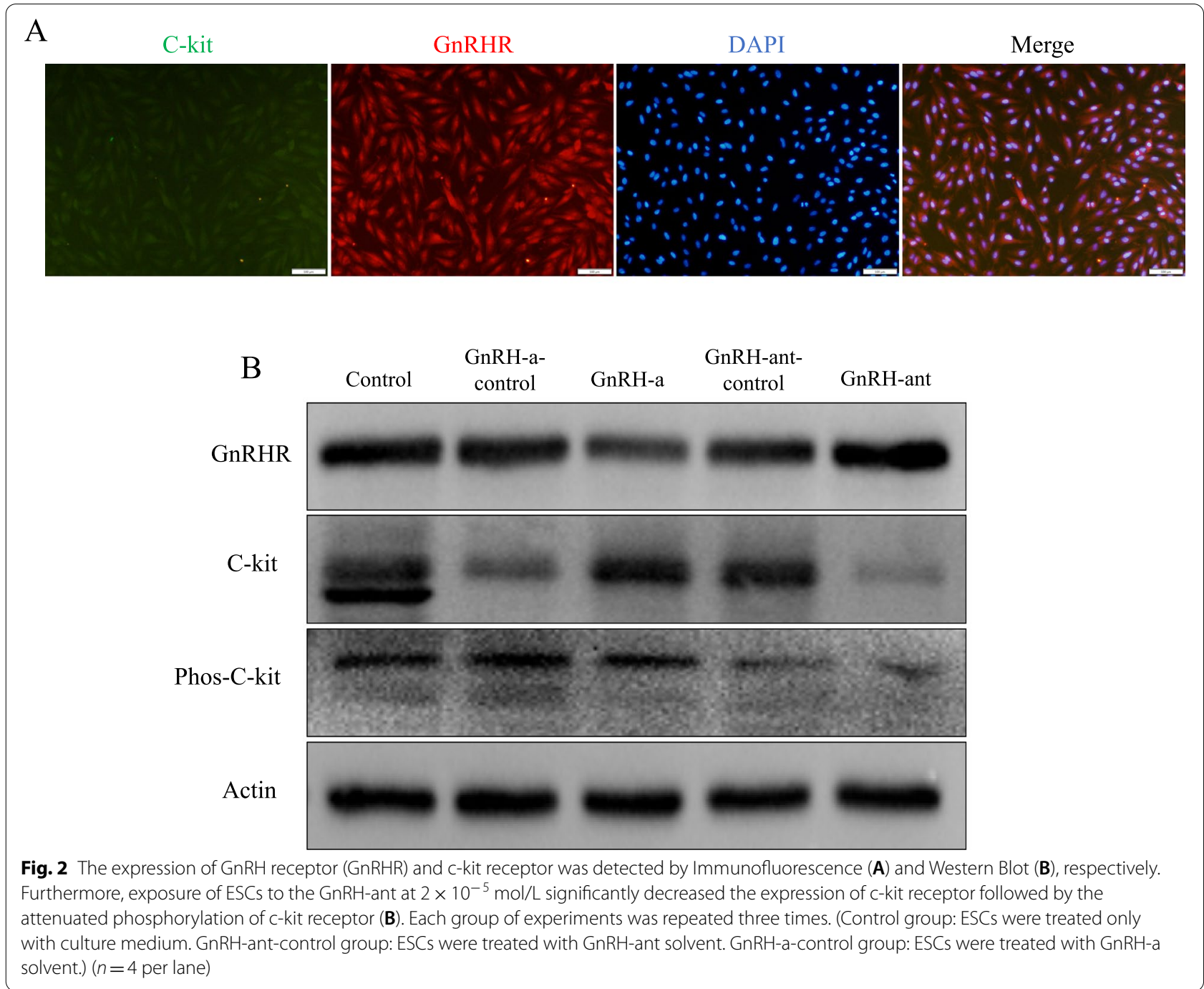




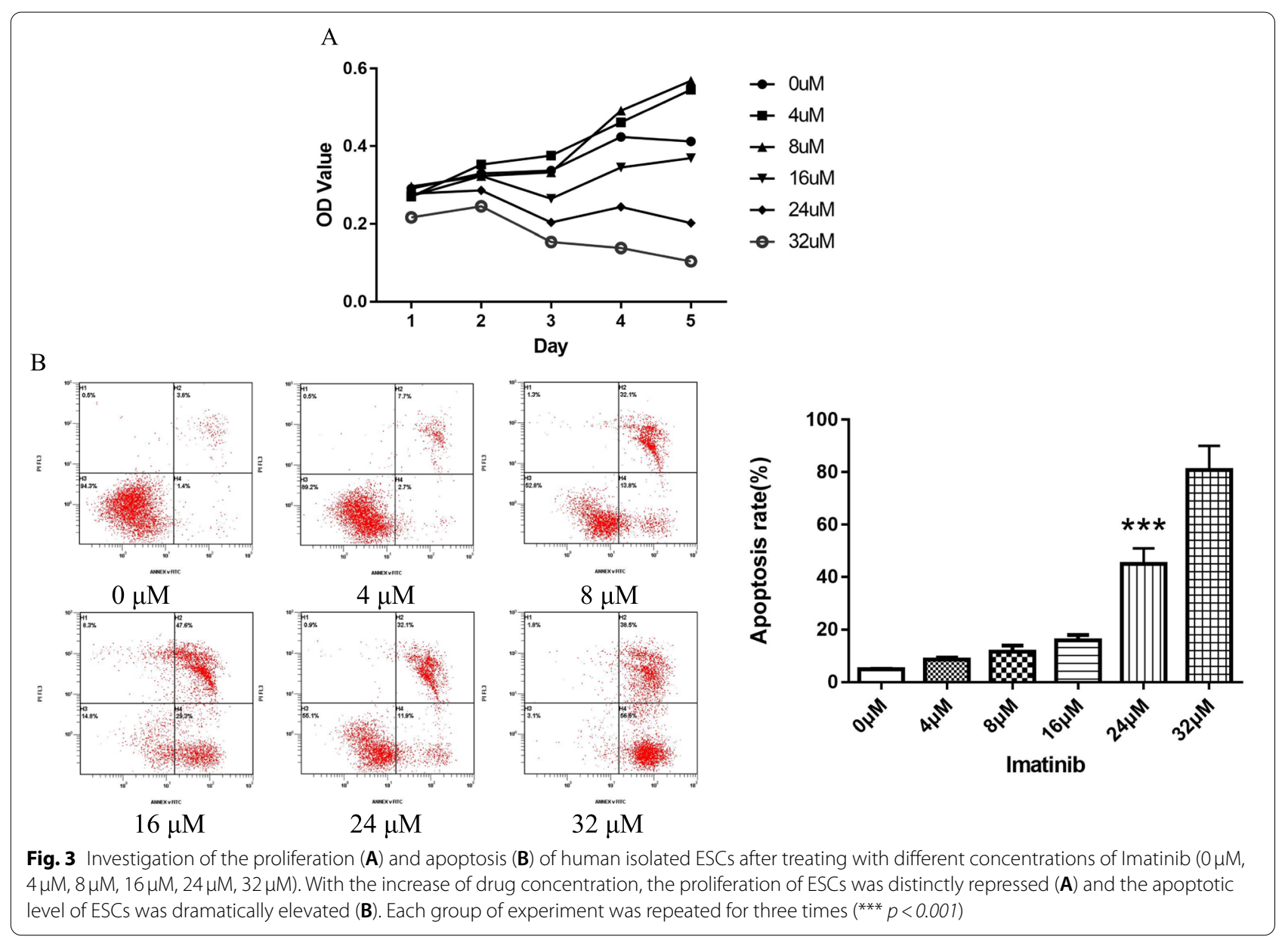

that with the increase concentration of imatinib, the reduction of proliferation and induction of apoptosis in ESCs were increasingly notable (Fig. 3). Due to most of ESCs were dead at $32 \mu \mathrm{M}$, we selected $24 \mu \mathrm{M}$ concentration as the ideal dosage to treat ESCs. The results showed that after inhibiting the c-kit receptor activation by $24 \mu \mathrm{M}$ imatinib in ESCs, the phosphorylation of AKT and the expression of cyclin D1 were significantly decreased (Fig. 4).

\section{Discussion}

In the normal menstrual cycle, endometrium would go through three phases: menstrual period, proliferative period and decidual period. During the decidual phase, the endometrium transformed into a receptive tissue that was suitable for embryo implantation [23, 24]. In this process, ESCs were the main cell type providing nutrition for the implanting embryos [25]. Therefore, the abundant numbers of ESCs would directly decide the success of embryo implantation. In the present study, although there were no differences in embryo quality between $\mathrm{GnRH}$-ant and GnRH-a group, GnRH-ant group produced lower rates of HCG positive, embryo implantation and clinical pregnancy. It was worth noting that a thinner endometrial thickness was observed in GnRHant group, suggesting that the appropriate endometrial thickness might be conducive to embryo implantation. Similar with our findings, many recent studies also found that the thinner endometrium was evidently related to the worse clinical outcomes in fresh and frozen-thaw embryo transfer [26-29]. One of the reasons resulting in worse clinical outcomes in $\mathrm{GnRH}$-ant group might be the adverse effect of GnRH-ant on growth ability of human ESCs. Accordingly, we isolated human ESCs from human endometrial tissues and treated cells with different concentrations of $\mathrm{GnRH}$-analog to investigate the effects of $\mathrm{GnRH}$-ant on the growth ability of ESCs. GnRH-ant significantly depressed the proliferation and promoted the apoptosis of ESCs, confirming the adverse influences of GnRH-ant on ESCs growth. However, how GnRH-ant negatively regulates the growth of ESCs is still unclear.

Previous studies have reported the positive effects of c-kit receptor on growth ability of multiple kinds of cells [30-33]. Furthermore, recent studies have found the 


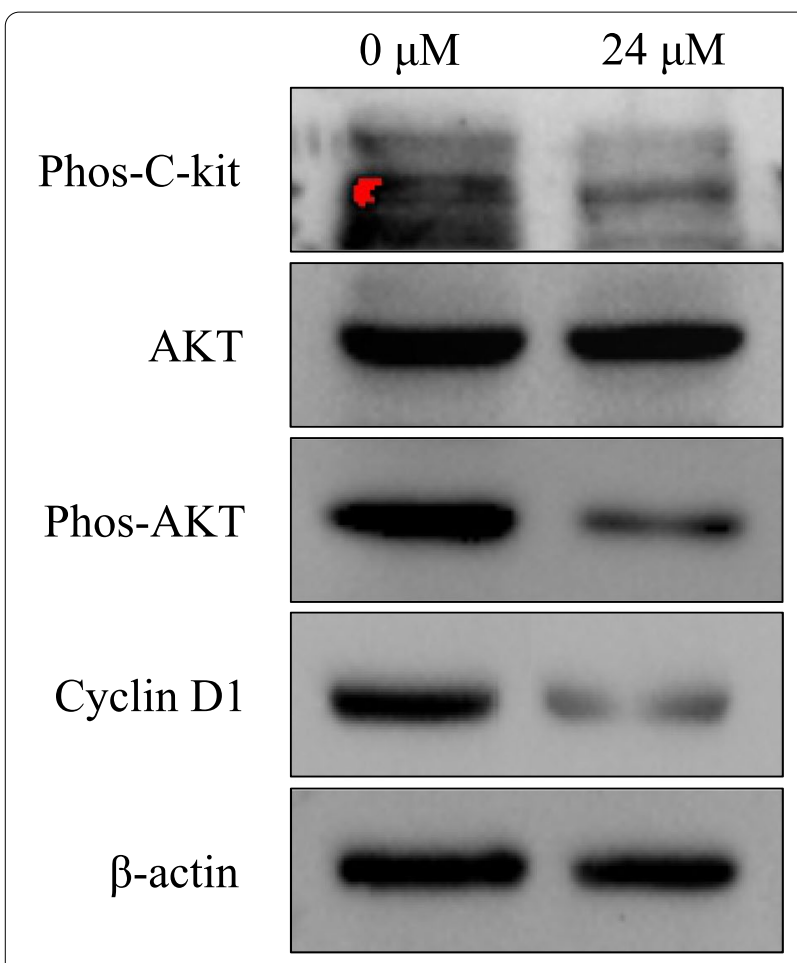

Fig. 4 After inhibiting the activation of c-kit receptor by treating ESCS with Imatinib $(24 \mu \mathrm{M})$, the phosphorylation of AKT and the expression of Cyclin D1 were significantly diminished. Each group of experiment was repeated for three times ( $n=4$ for per lane)

expression of c-kit receptor on animal embryo and endometrium, and proposed its important role in the process of embryo implantation [15]. Surprisingly, we found the expression of c-kit receptor on human ESCs, indicating that c-kit receptor might also regulate the growth ability of human ESCs. Whereafter, we treated human ESCs with imatinib (c-kit receptor inhibitor) and found that after inhibiting the activation of c-kit receptor by imatinib, ESCs showed remarkably decreased proliferation capacity and increased apoptosis level. Moreover, the phosphorylation of AKT and the expression of cyclin D1, which were closely associated with cell growth, were significantly weakened. These findings supported that activating c-kit receptor could accelerate the growth ability of human ESCs.

Based on the above findings, it is reasonable to speculate that whether the adverse effects of GnRH-ant on human ESCs growth ability is correlated with the inactivation of c-kit receptor? To further verify our hypothesis, we subsequently treated ESCs with GnRH-ant at $2 \times 10^{-5} \mathrm{~mol} / \mathrm{L}$ for $120 \mathrm{~h}$. The results showed that GnRH-ant significantly suppressed the expression of c-kit receptor followed by the attenuated phosphorylation of c-kit receptor, implying that GnRH-ant could weaken the growth ability of human ESCs by impairing the activation level of c-kit receptor through suppressing c-kit receptor expression. Notably, recent study directed by Chen et al. have demonstrated that GnRHant could disrupt human endometrial epithelial cells (EECs) migration by reducing the CKB expression, which altered endometrial receptivity [34]. Complementally, our findings showed another negative effect of GnRH-ant on ESCs, which was the repression of ESCs growth capacity. Even so, the whole effects of GnRH-ant protocol on endometrium of women undergoing IVF-ET were still unclarified. Hence, further researches related the molecular mechanism are needed.

Normally, the levels of endogenous GnRH in peripheral blood circulation were very low, thus, the biological functions resulting from the combination of $\mathrm{GnRH}$ and $\mathrm{GnRH}$ receptor outside the pituitary were very fewer [35]. Furthermore, GnRH-ant has greater affinity to GnRH receptor than GnRH and GnRH-a [36]. Therefore, GnRH-ant was more likely to combine with $\mathrm{GnRH}$ receptor outside the pituitary, such as endometrium [37]. Actually, several studies have found the time- and dose dependent growth suppressive functions of $\mathrm{GnRH}$-ant in various cancer cell lines, including endometrium cancer, ovary cancer and breast cancer [38, 39]. Although the specific molecular mechanisms were still unclear, it was reasonable to believe that the signaling mechanisms of GnRH- receptor in pituitary were not involved in inhibitory growth effects of GnRH-ant in cancer cells. Although the present study demonstrated the inhibitory effects of GnRHant on ESCs growth ability, these mechanisms were not enough to fully explain the results of women undergoing the GnRH-ant protocol. Therefore, more in-depth studies were still needed.

\section{Conclusion}

In brief, GnRH-ant attenuated the activation level of c-kit receptor by decreasing its expression in ESCs. Subsequently, this impaired effect could further inhibit the phosphorylation of AKT and lessened the expression of cyclin D1, which resulted in the reduction of growth ability of ESCs. The present study provides a new insight into the role of $\mathrm{GnRH}$-ant and suggests that the adverse effects of GnRH-ant protocol on endometrium should be considered before using in IVF-ET.

\section{Abbreviations}

GnRH-ant: Gonadotropin-releasing hormone antagonist; GnRH-a: Gonadotropin-releasing hormone agonist; GnRHR: Gonadotropin-releasing hormone receptor; ESCs: Endometrial stromal cells; EECs: Endometrial epithelial cells; IVF-ET: In vitro fertilization-embryo transfer; RTK: Receptor tyrosine kinase; BMI: Body mass index; AFC: Antral follicle count; $\mathrm{AMH}$ : Anti-mullerian hormone; rhFSH: Recombinant human FSH. 


\section{Supplementary Information}

The online version contains supplementary material available at https://doi. org/10.1186/s12958-021-00886-y.

Additional file 1: Supplementary Figure 1. ESCs was verified by immunohistochemical analysis. As shown in results, the expression of vimentin but not cytokeratin was found in human isolated ESCs.

\section{Acknowledgements}

The authors thank all the staff, nurses, and physicians at the Reproductive Medicine Center for their support in generating this manuscript.

\section{Authors' contributions}

Conception and design of the study: Ding-Fei Xu and Jun Tan. Cell biology experiments: Pei-Pei Liu, Lu-Fan and Qi Xie. Data analysis and interpretation: Zhi-Qin Zhang. Draft of the manuscript: Ding-Fei Xu and Jun Tan. Supervision and critical revision of the manuscript for important intellectual content: Jun Tan, Qiong-Fang Wu and Li-Qun Wang. Final approval of the version to be published: Ding-Fei Xu, Pei-Pei Liu, Lu-Fan, Qi Xie, Jun Tan, Qiong-Fang Wu and Li-Qun Wang. All authors have read, and confirm that they meet the authorship criteria. The author(s) read and approved the final manuscript.

\section{Funding}

This work was supported by the National Natural Science Foundation of China (81960271 and 81960288), the Major Research and Development Project of Science and Technology Department of Jiangxi Province (20192BBGL70005 and 20203BBGL73140) and the China Postdoctoral Science Foundation (2019M662272).

\section{Availability of data and materials}

All data generated and analyzed in this study are included in this published manuscript.

\section{Declarations}

\section{Ethics approval and consent to participate}

This study was conducted in accordance with the guidelines of the Declaration of Helsinki and was approved by the Clinical Ethical Committee of Jiangxi Maternal and Child Health Hospital, and informed consents from patients were obtained before the initiation of the study. All the authors consented to participate in this study.

\section{Consent for publication}

All the authors consented for publication.

\section{Competing interests}

The authors declared no potential conflicts of interest with respect to the research, authorship, and/or publication of this article.

\section{Author details}

${ }_{1}^{1}$ Jiangxi Medical College, Nanchang University, Nanchang, Jiangxi 330006, P. R. China. ${ }^{2}$ Reproductive Medicine Center, Maternal and Child Health Hospital Affiliated to Nanchang University, Jiangxi Maternal and Child Health Hospital, Nanchang, Jiangxi 330006, P. R. China. ${ }^{3}$ Department of Reproductive Health, Maternal and Child Health Hospital of Nanchang University, Jiangxi maternal and child health hospital, Nanchang, Jiangxi 330006, P. R. China.

Received: 26 August 2021 Accepted: 24 December 2021

Published online: 04 February 2022

\section{References}

1. Gobello C. New GnRH analogs in canine reproduction. Anim Reprod Sci. 2007;100(1):1-13.

2. Devroey P, Aboulghar M, Garcia-Velasco J, et al. Improving the patient's experience of IVF/ICSI: a proposal for an ovarian stimulation protocol with GnRH antagonist co-treatment. Hum Reprod. 2009;24:764-74.
3. Al-Inany HG, Abou-Setta AM, Aboulghar M. Gonadotrophinreleasing hormone antagonists for assisted conception: a Cochrane review. Reprod BioMed Online. 2007:14:640-9.

4. Orvieto R, Patrizio P. GnRH agonist versus $\mathrm{GnRH}$ antagonist in ovarian stimulation: an ongoing debate. Reprod BioMed Online. 2013;26:4-8.

5. Lambalk CB, Banga FR, Huirne JA, et al. GnRH antagonist versus long agonist protocols in IVF: a systematic review and meta-analysis accounting for patient type. Hum Reprod Update. 2017;23:560-79.

6. Bukulmez O, Carr BR, Doody KM, et al. Serum cetrorelix concentrations do not affect clinical pregnancy outcome in assisted reproduction. Fertil Steril. 2008;89:74-83.

7. Eftekhar M, Dehghani Firouzabadi R, Karimi H, et al. Outcome of cryopreserved-thawed embryo transfer in the $\mathrm{GnRH}$ agonist versus antagonist protocol. Iran J Reprod Med. 2012;10:297-302.

8. Gao G, Cui X, Li S, Ding P, Zhang S, Zhang Y. Endometrial thickness and IVF cycle outcomes: a meta-analysis. Reprod BioMed Online. 2020;40(1):124-33.

9. Jigal H, Ramsey S, Eran Z, et al. Endometrial compaction (decreased thickness) in response to progesterone results in optimal pregnancy outcome in frozen-thawed embryo transfers. Fertil Steril. 2019;112(3):503-9.

10. Zhang T, Li Z, Ren X, et al. Endometrial thickness as a predictor of the reproductive outcomes in fresh and frozen embryo transfer cycles: a retrospective cohort study of 1512 IVF cycles with morphologically goodquality blastocyst. Medicine (Baltimore). 2018;97(4):e9689.

11. Gallos ID, Khairy M, Chu J, et al. Optimal endometrial thickness to maximize live births and minimize pregnancy losses: analysis of 25,767 fresh embryo transfers. Reprod BioMed Online. 2018;37(5):542-8.

12. Fang R, Cai L, Xiong F, Chen J, Yang W, Zhao X. The effect of endometrial thickness on the day of HCG administration on pregnancy outcome in the first fresh IVF/ICSI cycle. Gynecol Endocrinol. 2016;32(6):473-6.

13. Lu Y, Niu Y, Wang Y, et al. Optimal candidates to do fresh embryo transfer in those using Oral contraceptive pretreatment in IVF cycles. Front Physiol. 2021;12:576917.

14. Ren JZ, Han DM, Sha AG, et al. The correlation between endometrial thickness and pattern in predicting outcome of in vitro fertilization and embryo transfer. Chin J Birth Health Hered. 2013;21(2):107-10.

15. Cabezas J, Lara E, Pacha P, et al. The endometrium of cycling cows contains populations of putative mesenchymal progenitor cells. Reprod Domest Anim. 2014;49(4):550-9.

16. Liang J, Wu YL, Chen BJ, et al. The C-kit receptor-mediated signal transduction and tumor-related diseases. Int J Biol Sci. 2013;9(5):435-43.

17. Stankov K, Popovic S, Mikov M. C-KIT signaling in cancer treatment. Curr Pharm Des. 2014;20(17):2849-80.

18. Tan J, Zou Y, Huang ZH, et al. C-kit signaling promotes human preimplantation 3PN embryonic development and blastocyst formation. Reprod Biol Endocrinol. 2019;17(1):75.

19. Gardner DK, Schoolcraft WB. In vitro culture of human blastocyst. In: Jansen R, Mortimer D, editors. Towards reproductive certainty: infertility and genetics beyond. Carnforth: Parthenon Press; 1999. p. 378-88.

20. Chou CS, MacCalman CD, Leung PC. Differential effects of gonadotropinreleasing hormone I and II on the urokinase-type plasminogen activator/ plasminogen activator inhibitor system in human decidual stromal cells in vitro. J Clin Endocrinol Metab. 2003:88:3806-15.

21. Wu HM, Huang HY, Lee $C L$, et al. Gonadotropin-releasing hormone type II $(\mathrm{GnRH}-\mathrm{II})$ agonist regulates the motility of human Decidual endometrial stromal cells: possible effect on embryo implantation and pregnancy. Biol Reprod. 2015;92(4):98.

22. Tan J, Yang S, Shen P, et al. C-kit signaling promotes proliferation and invasion of colorectal mucinous adenocarcinoma in a murine model. Oncotarget. 2015;6(29):27037-48.

23. Al Chami A, Saridogan E. Endometrial polyps and subfertility. J Obstet Gynaecol India. 2017;67(1):9-14

24. Okada H, Tsuzuki T, Murata H. Decidualization of the human endometrium. Reprod Med Biol. 2018;17(3):220-7.

25. Su RW, Fazleabas AT. Implantation and establishment of pregnancy in human and nonhuman primates. Adv Anat Embryol Cell Biol. 2015;216:189-213.

26. Liu KE, Hartman M, Hartman A, et al. The impact of a thin endometrial lining on fresh and frozen-thaw IVF outcomes: an analysis of over 40000 embryo transfers. Hum Reprod. 2018;33(10):1883-8. 
27. Kasius A, Smit JG, Torrance HL, et al. Endometrial thickness and pregnancy rates after IVF: a systematic review and meta-analysis. Hum Reprod Update. 2014;20(4):530-41.

28. Amir W, Micha B, Ariel H, et al. Predicting factors for endometrial thickness during treatment with assisted reproductive technology. Fertil Steril. 2007;87(4):799-804.

29. Richter K, Bugge K, Bromer J, et al. Relationship between endometrial thickness and embryo implantation, based on 1294 cycles of in vitro fertilization with transfer of two blastocyst-stage embryos. Fertil Steril. 2007:87(1):53-9.

30. Figueira MI, Cardoso HJ, Correia S, Maia CJ, Socorro S. Hormonal regulation of c-KIT receptor and its ligand: implications for human infertility? Prog Histochem Cytochem. 2014;49(1-3):1-19.

31. Berger SA. Signaling pathways influencing SLF and c-kit-mediated survival and proliferation. Immunol Res. 2006;35(1-2):1-12.

32. Cardoso HJ, Figueira MI, Correia S, Vaz CV, Socorro S. The SCF/C-KIT system in the male: survival strategies in fertility and cancer. Mol Reprod Dev. 2014;81(12):1064-79.

33. Kim JO, Kim HN, Kim KH, et al. Development and characterization of a fully human antibody targeting SCF/C-kit signaling. Int J Biol Macromol. 2020;159:66-78

34. Chen Q, Fan Y, Zhou X, et al. GnRH antagonist alters the migration of endometrial epithelial cells by reducing CKB. Reproduction. 2020;159(6):733-43.

35. Ortmann O, Diedrich K. Pituitary and extrapituitary actions of gonadotrophin-releasing hormone and its analogues. Hum Reprod. 1999;14(Supplement 1):194-206.

36. Reissmann T, Schally AV, Bouchard P, Riethmiiller $H$, Engel J. The LHRH antagonist cetrorelix: a review. Hum Reprod Update. 2000;6(4):322-31.

37. Ramakrishnappa N, Rajamahendran R, Lin YM, Leung PC. GnRH in non-hypothalamic reproductive tissues. Anim Reprod Sci. 2005;88(1-2):95-113.

38. Emons G, Grundker C, Gunthert AR, Westphalen S, Kavanagh J, Verschraegen C. GnRH antagonists in the treatment of gynecological and breast cancers. Endocr Relat Cancer. 2003;10(2):291-9.

39. Dondi D, Festuccia C, Piccolella M, Bologna M, Motta M. GnRH agonists and antagonists decrease the metastatic progression of human prostate cancer cell lines by inhibiting the plasminogen activator system. Oncol Rep. 2006;15(2):393-400.

\section{Publisher's Note}

Springer Nature remains neutral with regard to jurisdictional claims in published maps and institutional affiliations.

Ready to submit your research? Choose BMC and benefit from:

- fast, convenient online submission

- thorough peer review by experienced researchers in your field

- rapid publication on acceptance

- support for research data, including large and complex data types

- gold Open Access which fosters wider collaboration and increased citations

- maximum visibility for your research: over 100M website views per year

At BMC, research is always in progress.

Learn more biomedcentral.com/submissions 